in the common duct, in which it is paramount to remove the stones; and when we drain we cure the patient. In the cholecystectomy cases Dr. Archibald goes a step farther , and drains through the cystic duct. He cures three out of four patients. Remove the gallbladder whenever wise and safe in cases of chronic pancreatitis and drain.

Dr. E. Starr Judd, Rochester, Minn.: Our experimental work on pancreatitis was brought about entirely by the researches of Dr. Archibald years ago, and it may be at variance with his work at the present time. This work was entirely original so far as Dr. Archibald is concerned. We thought, as our experiments went along, that while they were a little different from Dr. Archibald's, that we were coming to the same conclusions. The assumption was that pancreatitis was due to bile entering the pancreatic duct, because of the action of the sphincter. Archibald proposed to cure pancreatitis by paralyzing Oddi's sphincter. Dr. W. J. Mayo called attention to the fact that clinical evidence shows that removal of the gallbladder is a good procedure, in gallbladder cases, when the pancreas is involved. I remember the first case illustrating this point. The original treatment for chronic pancreatitis was drainage of the gallbladder. It had been drained twice, and all symptoms were relieved, which was the history in most of our cases of pancreatitis that were drained. At the third operation the pancreas was definitely enlarged and there were many adhesions about the gallbladder. It was so badly lacerated that it was impossible to do a cholecystotomy so the gallbladder was removed. The man was watched carefully, with the idea that he might have trouble, that possibly we might have taken away a safety valve. However, he promptly got well and remained well.

Unless there is definite mechanical obstruction in the common duct cholecystenterostomy is useless. Permanent bile drainage cannot be established in that way. The reason we believe that cholecystectomy is a better procedure in panreatitis is that in every case in which the gallbladder is removed, the common duct dilates until its increased capacity compensates for the loss of the gallbladder, or the sphincter becomes incontinent. This dilatation has been mentioned by many observers when there is obstruction of the duct. In the experimental work of removing the gallbladder, conducted by Dr. Mann, we found what we thought was a definite enlargement in the common duct, and as nearly as it could be estimated in a large percentage of the dogs and cats, a definite dilatation existed in this duct. We tried to estimate how this took place, and it seemed to be due to fluctuation in pressure. The resistance offered by the liver itself was greater than that offered by the walls of the extra hepatic ducts or the sphincter. We prestume that this fluctuation in pressure eventually brought about what $\mathrm{Dr}$. Archibald was doing in experimental work on the sphincter. It seemed that the dilatation in the duct continued until there was enough hypertrophy in the wall to overcome the resistance offered by the little sphincter in the ampulla. When that took place we had paralysis of the Oddi sphincter and a continuance of the entrance of bile into the duodenum. In this way we had an explanation of how removal of the galibladder might possibly cure cases of pancreatitis.

Dr. J. EArL Else, Portland, Ore.: As has been stated, regurgitation of bile is a cause of pancreatitis. In a case seen at postmortem, Nature took care of a regurgitation of bile into the pancreas without leaving any evidence of inflammation although there was undoubtedly some present at one time. The outlet of the ampulla of Vater was almost completely occluded so that pressure on the gallbladder would force only a drop of bile at a time from it. The bile flowed freeiy from a persistent duct of Santorini. Dissection showed about $6 \mathrm{~cm}$. of the lower portion of the duct of Wirsung to be dilated. From the upper end of the dilated portion a large anastomotic branch led over to the duct of Santorini so that the bile passed up the duct of Wirsung through the large anastomotic branch to the duct of Santorini and down through it to the duodenum. A search of the literature at hand failed to reveal a similar case.

Dr. R. C. Dugan, Ottawa, Kan.: Dr. William J. Mayo was the first surgeon I saw remove the mucous membrane of the gallbladder instead of removing the whole gallbladder. It was done as the operation of necessity because he could not remove the whole gallbladder. Recently, I have been doing that operation by election and I think I get better results in many cases than from a complete cholecystectomy. The pouch of peritoneum left after the removal of the mucous membrane of gallbladder gives opportunity to drain as long as we want to, and when drainage is removed, the gallbladder is practically removed as far as function is concerned.

Dr. Edward W. Archibald, Montreal, Canada: In cases of pancreatitis where there is infection and the gallbladder is removed and the common duct drained, it will be better to drain the common duct a long while rather than a short while. I have a profound admiration for the work that is going on in the Mayo Clinic; work which is not merely clinical, but is reaching out into the domain of experimental surgery. We must all regard such work as being nowadays a necessary complement to clinical work in any clinic of high standing. By it alone, we can get light on many problems. By comparing and discussing our results, as we have done today, we shall ultimately have complete knowledge of this subject.

\section{FURTHER EXPERIENCES WITH THE KONDOLÉON OPERATION FOR ELEPHANTIASIS *}

\author{
W. E. SISTRUNK, M.D. \\ ROCHESTER, MINN.
}

I wish to discuss in this paper the merits of the Kondoléon operation for elephantiasis and to report the results obtained in seven patients operated on by the method.

Kondoléon $^{1}$ of Athens, Greece, in 1912, first reported cases of elephantiasis in which operation was performed by his method. The operation seems to have been gradually evolved through others of a similar though distinctly different type, which had been performed by Lanz, ${ }^{2}$ Oppel $^{3}$ and Rosanow, ${ }^{4}$ and its aim is to establish, by a wide excision of the aponeurosis, a communication between the superficial and deep lymphatic channels. The deep aponeurosis seems distinctly to separate the superficial from the deep group of lymphatics. In elephantiasis, the edematous and hypertrophied tissues are found to lie above the aponeurosis, while the subaponeurotic tissues are usually quite normal. When large pieces of this tissue are removed, sufficient communication may be established to allow the deeper group of lymphatics and the muscles to drain the stagnant lymph ordinarily handled by the blocked superficial group, and this very markedly benefits the condition. The technic of Kondoléon's operation is as follows:

Long incisions are made along the outer and inner aspects of the affected limb, and through each of these a large slice of edematous fat is removed. The aponeurosis is then opened and a portion of it, three or four fingers in width, is excised throughout the entire length of the skin incision. The wound is then

* From the Mayo Clinic.

* Read before the Section on Surgery, General and Abdominal, at the Sixty-Ninth Annual Session of the American Medical Association, Chicago, June, 1918

1. Kondoleon, E.: Die chirurgische Behandlung der elefantiastischen Oedeme durch eine neue Methode der Lymphableitung, München. med. Wchnschr., 1912, 59, 2726.2729; Die operative Behandlung der elefantiastischen Oedeme, Zentralbl. f. Chir., 1912, 39, 1022-1025; Die Dauer-resultate der chirurgischen Behandlung der elefantiastischen Lymphödem, München. med. Wchnschr., 1915, 62, 541-542.

2. Lanz: Eröffnung neuer Abfuhrwege bei Stauung in Bauch und unteren Extremitäten, Centralbl. f. Chir., 1911, 38, 152.155.

3. Oppel, V. A.: Conservative Operative Treatment of Elephantiasis, Khirurg. Arkh. Velyaminova, St. Petersburg, 1911, 27, 387-394.

4. Rosanow, W. N.: Lymphangioplastik bei Elefantiasis, Arch. f. klin. 
closed without drainage in such a way that the skin, with a small amount of subcutaneous fat attached to it, comes in contact with the exposed muscles.

The first article in this country calling attention to and commending this operation was published in 1913 by $\mathrm{Matas}^{5}$ of New Orleans. He discusses in detail the etiologic factors that contribute to the production of true elephantiasis, giving his own opinion and that of others regarding the part which bacteria, usually streptococci, play in the production of this condition, and emphasizing repeatedly the necessity of such bacterial invasion in order that a true elephantiasis may be produced. Lymphatic or venous stasis, from various causes, usually precedes and is the predisposing cause of the bacterial invasion, although, according to Matas, many writers, including Le Dantec, ${ }^{6}$ Sabouraud ${ }^{6}$ and Unna, ${ }^{6}$ believe that true elephantiasis may occur independently of lymphatic or venous obstruction and solely as a result of repeated attacks of streptococcic infection. Matas states that the histopathologic elements that are essential to complete the picture of elephantiasis are (1) a mechanical obstruction or blockade of the veins and lymphatics of the affected region, usually an obliterative thrombophlebitis or lymphangitis or adenitis ; (2) hyperplasia of the collagenous connective tissue of the hypoderm; (3) gradual disappearance of the elastic fibers of the skin; (4) the existence of a coagulable dropsy or hard lymphedema, a nd (5) a chronic reticular lymphangitis caused by secondary and repeated invasion of pathogenic micro-organisms of the streptococcic type. In conclusion he reports two cases in which operation was performed, one by himself and the other by his associate, Gessner, which were the first cases in this country in which the Kondoléon operation was used.

Royster, ${ }^{7}$ early in 1914, reported a case in which operation was performed by Kondoléon's method, and Hill, ${ }^{\mathrm{s}}$ in 1915 , reported a case in which the same procedure had been used. 5. Matas, Rudolph: The Surgical Treatment of Elephantiasis and and Venous Channels, Am. Jour. Trop. Dis. and Prev. Med., 1913, 1, and $\mathrm{V}-85$.

6. Quoted by Matas (Note 5 ).

7. Royster, H. A.: Elephantiasis and the Kondoléon Operation, THE JournAl A. M. A., May 30, 1914, p. 1720-1722.

334-335.
The operation has been performed in the Mayo Clinic in seven instances. I have reported three of these cases in a recent article on the subject. In three of the patients the disease was located in the left arm, and in the other four patients, in one of the lower extremities.

In the first arm case an elephantiasis had developed following an infected vaccination wound, with repeated

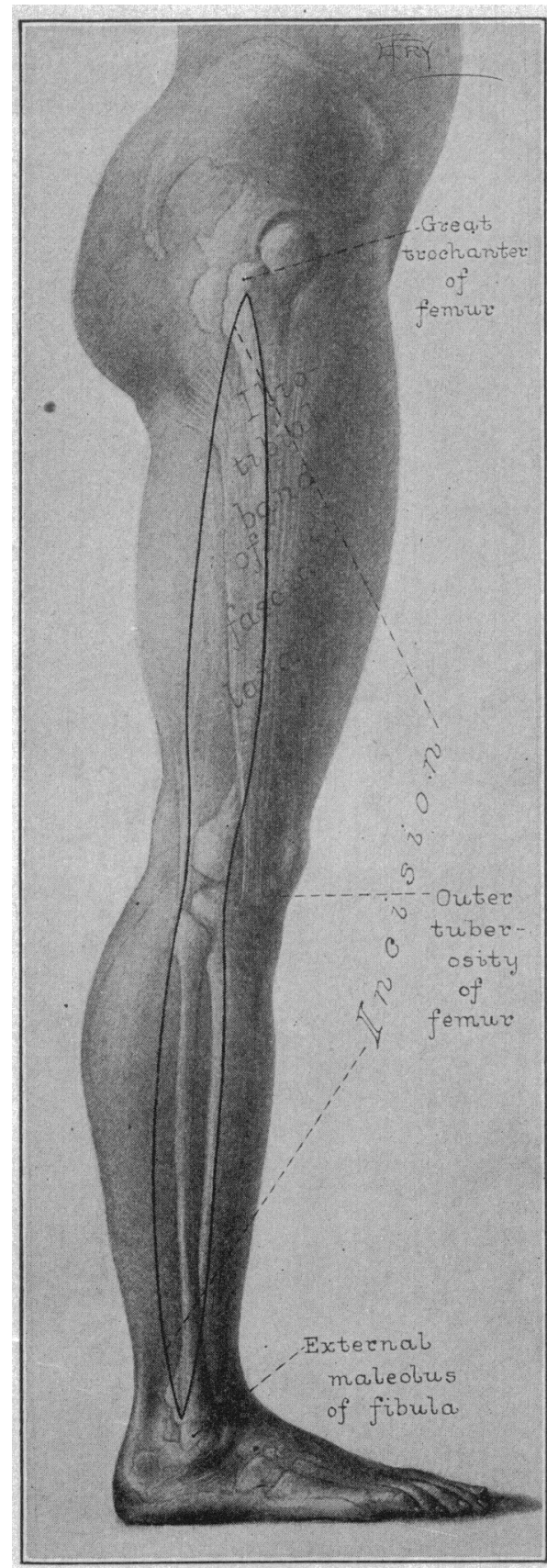

Fig. 1.-Line of incision on the outer surface of the 1.-Line of incis

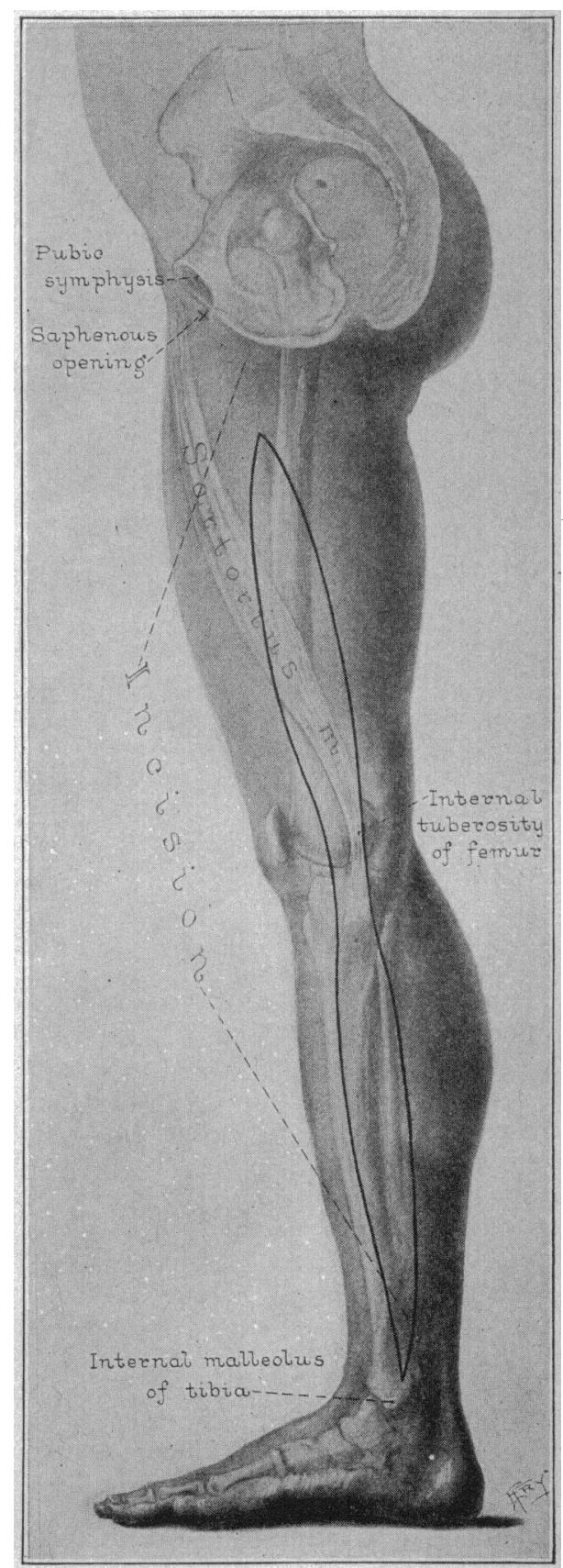

Fig. 2.-Line of incision on the inner surface Fig. 2 - Line of incisiog
of the leg and thigh.

erysipelatous attacks in the affected arm. The next arm case in which operation was performed was one of a simple lymphedema of the arm following the radical removal elsewhere of the left breast and axillary glands for a supposed malignant tumor of the breast, but which was afterwards proved to be benign. In the third arm case, an elephantoid condition had resulted from an injury to the arm two years previously. 
In one of the leg cases, a woman aged 23 , the condition was probably congenital, having been first noticed when the patient was a child $11 / 2$ years old. In another case of a girl, aged 17 years, who had had trouble for six years, no etiologic factor was obtainable. Her tonsils were septic, and were removed following the operation. The third leg case in which operation was performed was that of a child with a chronic tuberculosis synovitis of the knee and tuberculosis of the inguinal lymph nodes on the affected side. The fourth case was in a woman of 21 . The condition had developed six years previously, fol-

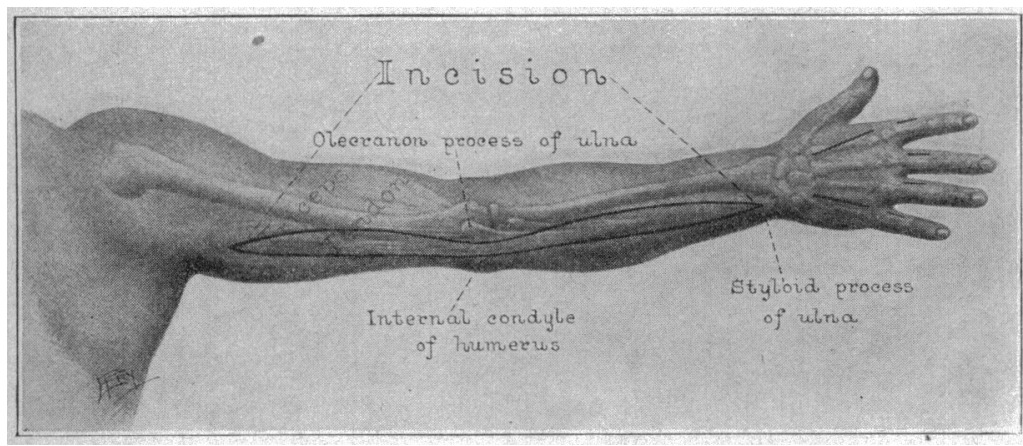

Fig. 3.-Line of incision on the outer surface of the arm and forearm.

lowing an attack of tonsillitis, with subsequent arthritis which was accompanied by fever. At the same time she also had four large boils on her face and right arm.

In all of the leg cases there was marked thickening of the dermal and hypodermal tissues with marked edema and thickening of the aponeurosis, but in none of these could a history of recurring erysipelatous attacks be obtained.

The results obtained in the arm cases were not so satisfactory as those in the leg cases. In each case improvement was quite marked shortly after the operation, but in two instances the patients still report some swelling which fluctuates in its extent. In the patient in whom the trouble had developed following vaccination, the arm and forearm have returned to normal, but a swelling of a fluctuating type still persists on the dorsal surface of the hand.

In all of the leg cases the improvement was very striking and occurred almost immediately following operation. In the first of these, operation was performed one and one-half years ago (previous to June, 1918), and the others eight months, four months and two months ago, respectively. All were heard from or seen during April or May, 1918, and in each case the improvement has been very marked and has persisted.

We were able to grow streptococci from the verrucose formations which were present in certain areas on the arm of the patient who developed elephantiasis following infection in the vaccination wound. However, although cultures were made from the edematous fat and thickened aponeurosis in nearly all of the other cases in which operation was performed, streptococci or other pathogenic organisms could not be grown. In the first patients operated on, no microscopic examinations were made of the tissues removed. In the later cases, however, careful examinations of these were made with the same findings as those reported by other writers. Dr. Broders, of the laboratory of fresh tissue diagnosis, has very kindly done this portion of the work and reports his findings as follows:

\section{EXAMINATION OF TISSUES}

Gross Pathology.-Grossly, the specimens examined presented a reduction in the thickness of the epidermis with a marked thickening of the dermis. A large amount of fat was present underneath the dermis, which was separated into lobules by fibrous connective tissue trabeculae. These trabeculae connected with the aponeurosis, which was also greatly thickened.

Microscopic Appearance of the Tissues. - Microscopically, there was a reduction in the thickness of the epidermis. The epithelial papillae were very much diminished in length and, in a number of areas, they had completely disappeared. The dermis showed a marked thickening and fibrosis. The sweat glands were partially compressed by the excess of fibrous tissue, while the veins and lymphatics were dilated. The elastic tissue of the skin had entirely disappeared. The fibrous trabeculae which separate the fat lobules and connect with the aponeurosis showed numerous dilated veins, capillaries and lymphatics, and also small groups of leukocytes. The aponeurosis presented a picture similar to that of the trabeculae. There were evidences of edema throughout the tissue.

\section{TECHNIC OF OPERATION}

In our first cases we followed as closely as possible the technic, as we understood it, which had been used by Kondoléon. We gradually realized that better results were obtained when a fair amount of hypertrophied skin was removed in addition to an extensive removal of the edematous fat, and that it was neces- 
to facilitate a wide removal of the subcutaneous fat, the skin is reflected on each side of the incision for a distance of about 1 or $11 / 2$ inches. The skin is retracted, and underneath each of the reflected skin edges, a long incision is made through the edematous subcutaneous fat down to and including the aponeurosis. These incisions are made almost parallel to the original skin incision. Included between them is a quadrilateral piece of edematous fat and aponeurosis. At the upper end, these two incisions through the aponeurosis are connected by a transverse incision. The tissues to be removed are now free except for the attachment of

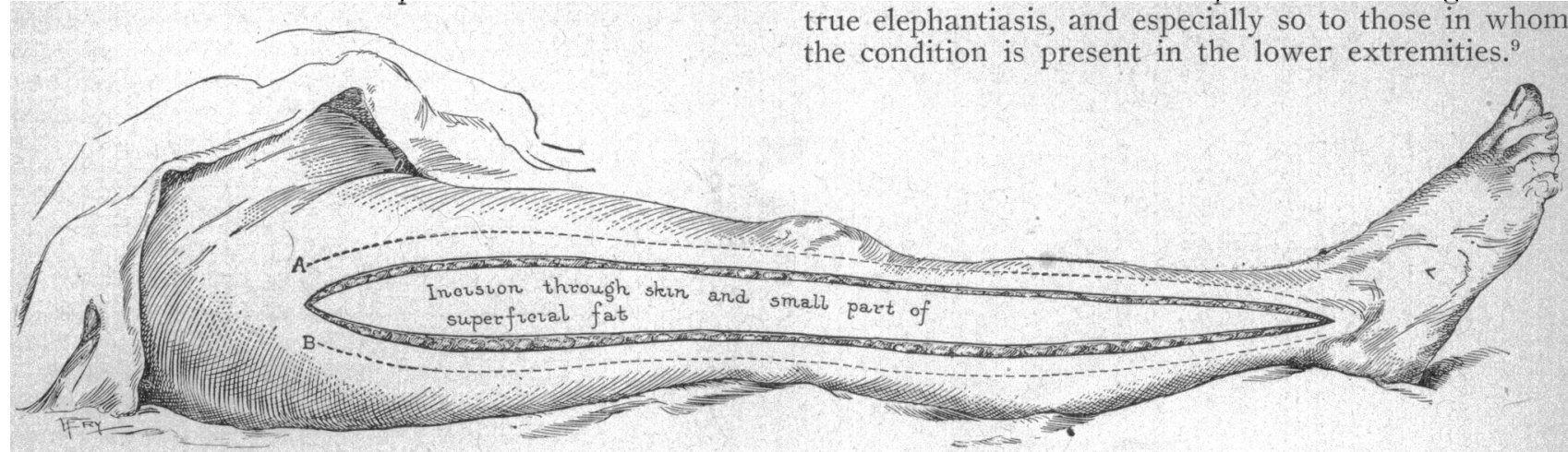

Fig. 5.-Incision used on the outer surface of the thigh and leg. Dotted lines $A$ and $B$ show extent to which the skin is reflected for the removal of subcutaneous fat.

the aponeurosis to the underlying muscles. By traction on the tissues that are to be removed, it is very easy to dissect the aponeurosis from the muscle throughout the length of the entire limb and to remove in one long piece the skin, edematous fat and aponeurosis. A number of vessels which tend to bleed profusely are encountered. These are temporarily controlled with forceps. After the tissue has been removed, these forceps are taken off, and surprisingly few of the
After operation, the patient is kept in bed for eight or ten days. An elastic bandage is then applied and the patient allowed to get up and walk about. We have advised the use of this elastic bandage for several months, and if there is a tendency toward swelling when it is removed, it should be worn for an indefinite period. The suggestion of Matas, to administer antistreptococcic serum or vaccine at intervals for some time after the operation, has been followed.

Our experience with the Kondoléon operation leads us to believe that in this we have a procedure whereby much aid can be offered to patients suffering with a true elephantiasis, and especially so to those in whom the condition is present in the lower extremities. ${ }^{9}$

\section{REPORT OF CASES}

CASE 1. (41167).-A woman, aged 21, with the congenital type of elephantiasis of the left leg, which had been present since she was $1 \frac{1}{2}$ years of age, was first seen in the Mayo clinic at the age of 15 . At that time there was a tremendous enlargement of the left foot, leg and thigh, and a marked thickening of the skin covering these. In August, 1911, according to Handly's method, one silk strand was placed on the outer and one on the inner aspect of the leg, from the ankle to the region of the left groin. The patient returned

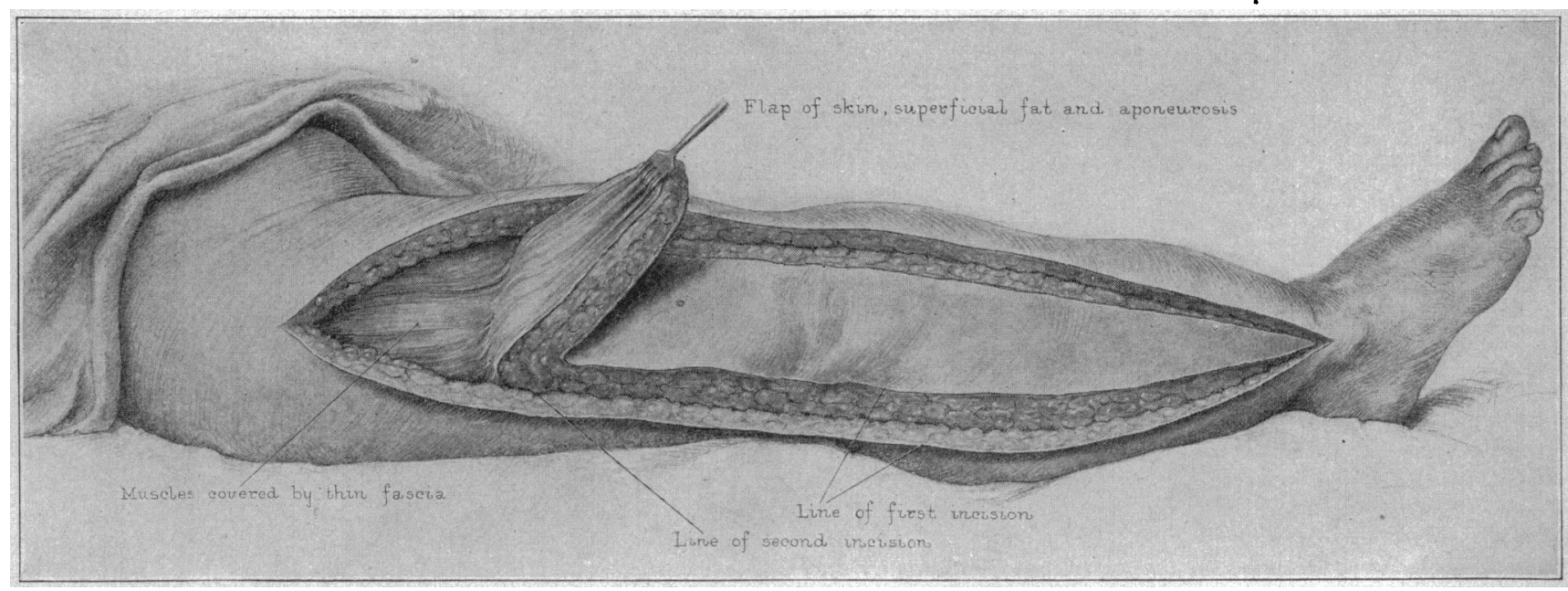

Fig. 6.-Skin, a large amount of subcutaneous fat, and aponeurosis removed in one piece.

vessels will be found to need ligatures. The wound is closed with interrupted silkworm-gut stitches, without drainage. It is necessary to do a similar operation on the opposite side of the limb. If the patient's condition permits, we usually do this as soon as the first operation has been completed; if not, after a period of eight or ten days has passed. The tissues, although diseased, heal remarkably well, and in none of the cases in which we have operated has there been the slightest infection (Figs. 1-7). six months later without improvement; in fact, the enlargement had increased. In February, 1912, a double silk strand was placed subcutaneously on the outer and inner aspects of the leg, and the inner of these strands was extended upward into the fat of the abdominal wall, while the outer strands were carried as high as the left axillary line. The condition remained unchanged until her return more than four years later. At this time, December, 1916, an operation of the Kondoléon type was done, first on the outer side of the leg,

9. Elliott, J. A.: Elephantiasis Nostras: Report of a Case, Jour. Cutan. Dis., 1917, 35, 17-25. 
and about one month later, on the inner side. The improvement was marked from the beginning, and at the time of her discharge, in March, 1917, the leg was much smaller than before the operation. A letter received in May, 1918, stated that the leg at present was smaller than when she left here,

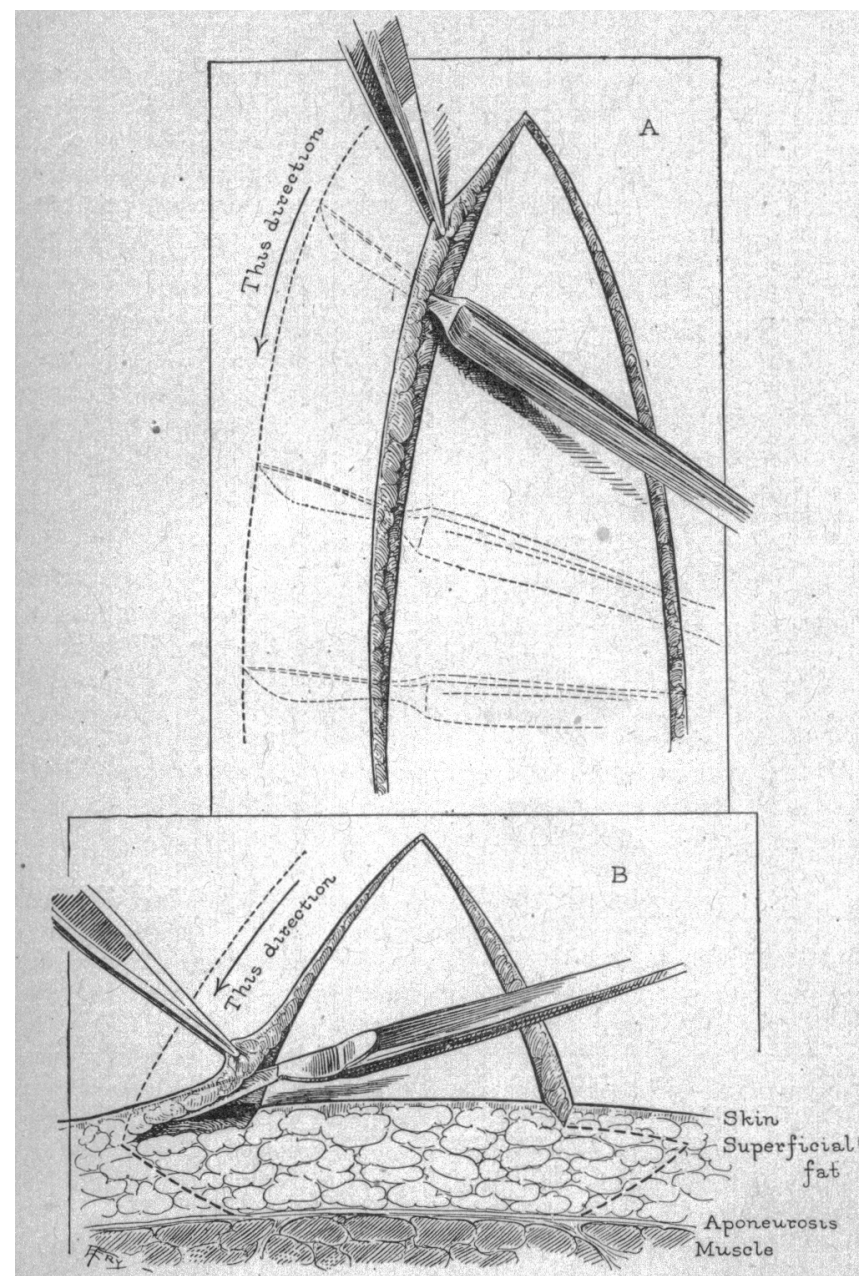

Fig. 7.- $A$, method used to facilitate the removal of a large amoun of subcutaneous fat. After the incision has been made the skin and a small amount of fat are reflected in order that a larger amount of fat may be removed. $B$, cross-section of $A$.

and that she was able to walk and even to run with but slight inconvenience.

CASE 2 (170799) -A woman, aged 20, with elephantiasis nostras, presented a history that was negative until she was 11 years of age, when there was a severe infection following vaccination on the left arm. After the vaccination wound healed she was in good condition until two years before coming to the clinic. At this time, swelling of the left hand had developed and had slowly progressed until the forearm and arm were involved in the process. She had had many attacks of erythema in the swollen portion. The history and findings in this case have been reported in detail by Elliott. At the time of our examination, July 9, 1917, the patient presented a diffuse swelling of the arm, forearm and hand. The swelling was much more marked in the hand and gradually diminished up to a point a few inches below the acromion process. It also involved the proximal phalanges of the fingers. There was a definite thickening of the skin. July 13 , an operation of the Kondoléon type was performed through incisions 5 or 6 inches long on the anterior and posterior surfaces of the arm and forearm. No incisions were made on the hand. Considerable.improvement followed in the arm and forearm, but the condition in the hand remained stationary and some swelling also remained about the elbow. A second operation was done, September 29, at which time two incisions were made on the dorsal surface of the hand and one on each of the lateral surfaces of the elbow. Multiple incisions were also made on each proximal phalanx of the fingers. The arm and forearm have returned practically to normal. Following the second operation there was considerable improvement for a while in the hand; later, however, the dorsal surface of the hand had a return of the swelling and at the present time (June, 1918) it is swollen.

CASE 3 (206558)-A woman, aged 51, had lymphedema of the left arm following amputation of the breast with removal of the axillary glands, done elsewhere. The wound had not been infected. Two months after the operation the arm began to swell, growing slowly but progressively worse and involving the dorsal surface of the hand, the forearm and the arm nearly as high as the shoulder joint. There was no thickening of the skin. Sept. 1, 1917, a Kondoléon type of operation was done. Long incisions were made on the outer and inner aspects of the arm and forearm from a point a few inches below the shoulder joint down to the wrist; also two incisions were made on the posterior surface of the hand. The swelling in the hand decreased at once, and there was marked improvement in the arm and forearm for a time. A recent letter (May, 1918), would lead us to infer that there is slightly more swelling at this time than there was when she was discharged from our care. This, however, is of a fluctuating character, and is less at times.

CAse 4 (216446) -A woman, aged 43, with an elephantoid condition of the left forearm, had a fall down stair-steps two years before being seen in the clinic, with injury to the left forearm. Three days later the skin on the outer surface of the forearm became red and then black, and remained so for two or three weeks. Three months later the forearm swelled and remained so until she was examined here in January. 1918. At times there was also swelling on the dorsal surface of the hand. When seen, the patient was found to have a

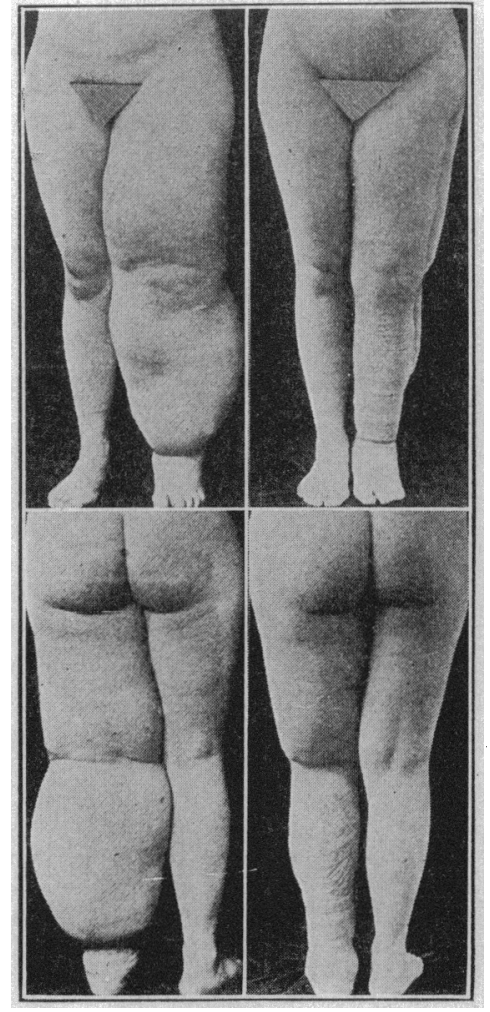

Fig. 8 (Case 1).-Anterior and pos terior views before and after operation.

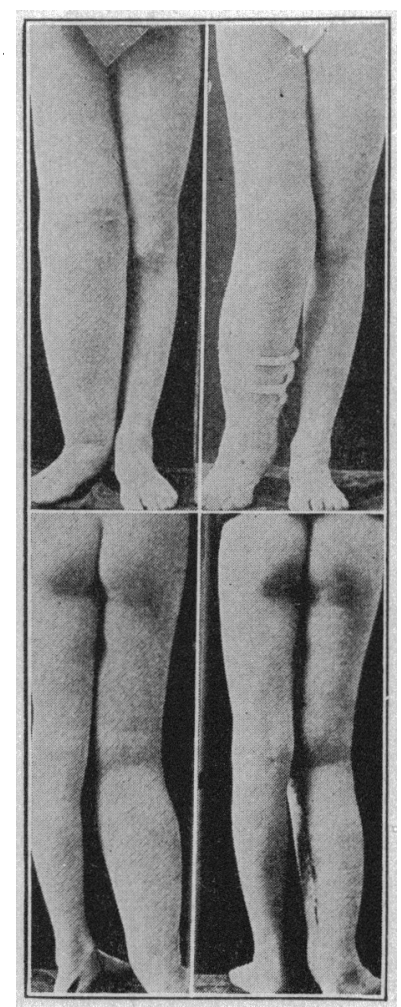

Fig. 9 (Case 6).--Anterior after operation. and posterior views before and

swelling of the left forearm, with considerable thickening of the skin. January 12, an operation of the Kondoléon type, similar to the one described in the previous cases, except for the fact that no incisions were made on the dorsal surface of the hand, was done. There was marked immediate improve- 
ment which persisted until April 1. The patient, in a recent letter, states that at this time the forearm from the elbow to the wrist became inflamed and full of red blotches. Following this the swelling returned and at the present time (June, 1918), the arm has been swollen for two months. She states

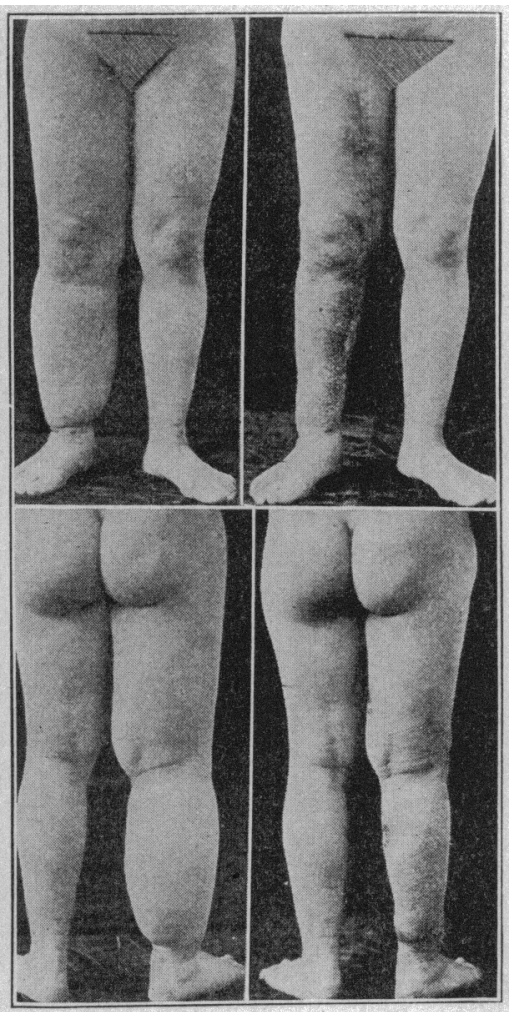

Fig 10 (Case 5)-Anterior and postetior views before and after operation.

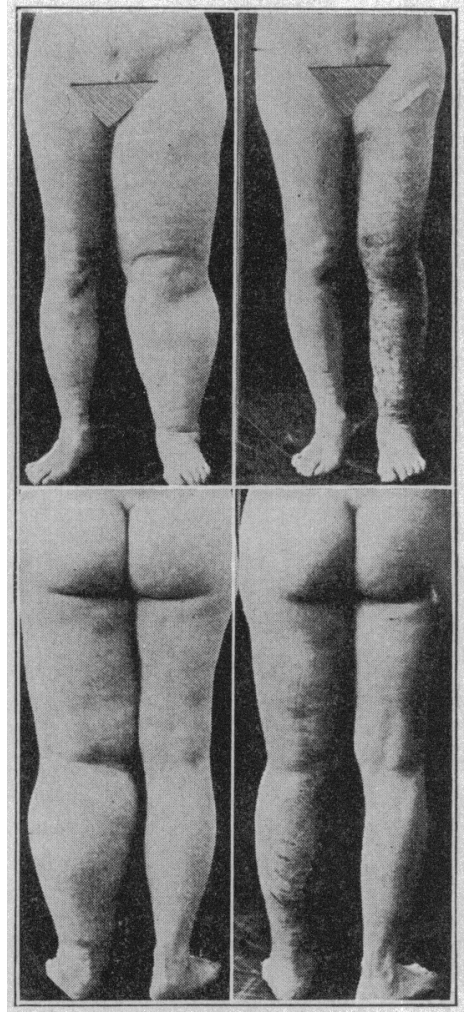
Fig. 11 (Case 7).-Anterior and pos-
terior views before and after operaterio
tion. that the swelling is nearly as marked now as before the operation.

CASE 5 (213799) -A girl, aged 17, had a negative history until 1912. At that time the right leg became swollen without apparent cause and remained so until she was seen here in November, 1917. No etiologic factor could be obtained. The patient had septic tonsils, which were removed after her operation. When examined, there was a very marked enlargement of the right leg and thigh, with thickening of the skin. An operation of the Kondoléon type was done, Nov. 27 1917. It was followed by marked improvement which has been permanent to the present time (June, 1918).

Case 6 (221137).-A girl, aged 12 , when $3 \frac{1}{2}$ years of age developed swelling on the inside of the right knee, which was followed by a swelling of the leg and thigh. The condition began one month after an attack of measles. She consulted us in February, 1918, at which time there was fairly marked swelling of the leg and thigh, with considerable thickening of the skin. She also had a tuberculous synovitis of the right knee joint, with

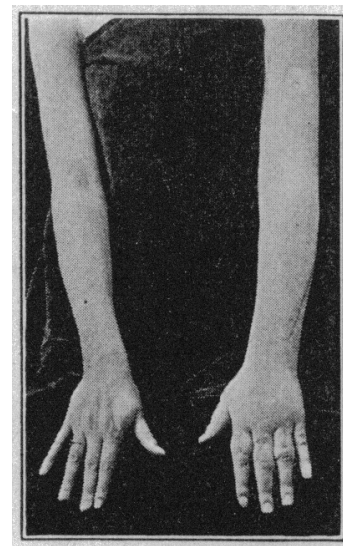

Fig. 12 (Case 2).-Three months after Kondolion peration. Unfortunately, no photograph was taken in tion. slight effusion into the joint, and a tuberculosis of the right inguinal glands. A Kondoléon operation was done, Feb. 12, 1918. This was followed by a very fair decrease in the size of the limb, which has remained stationary to the present time (June, 1918). The result following the operation in this patient was not quite so good as that obtained in the other patients in whom the condition was present in the leg.

CASE 7 (228071)-A woman, aged 21, five and one-half years before she was seen in the Mayo clinic, in 1918, developed tonsillitis which was followed by an arthritis with fever. At the same time there were several large boils on her face and right arm. Two and one-half years later the patient developed an amenorrhea, and during six weeks' time lost 30 pounds in weight. She was then told by her physician that she was anemic. The swelling in the right leg continued up to the date of her visit to this clinic, when there was a marked edema of the right leg with considerable thickening of the skin. A'Kondoléon operation was done on one side of the limb, April 20, and on the other side, April 30, 1918. It was followed by immediate and very marked improvement which has continued up to the present time (two months). In this instance the limb returned practically to a normal state.

\section{ABSTRACT OF DISCUSSION}

Dr. Hubert A. Royster, Raleigh, N. C.: Elephantiasis is not a very common disease, at least not in this country. We have been taught heretofore that the disease was caused by the Filaria sanguinis-hominis, or some of the parasites circulating in the blood. I venture to say that unless one has looked up this subject within the last year or so, that opinion would still be held by the majority of physicians. As a matter of fact, as shown by Matas, cases in the southern part of this country rarely exhibit filariae. The case which I had was the only case of true elephantiasis that I have seen and it did not show the Filaria sanguinis-hominis in the blood either by day or by night. This patient was operated on in January, 1914, by the method just described, the Kondoléon operation. Fortunately, I had just received and read carefully the exhaustive paper by Dr. Matas and I was able to give this man almost perfect relief; whereas experience by different surgeons with other cases had ended in sad failures. I do not wish to discuss this operation in detail, because Dr. Sistrunk has given practically all that is known about it at the present time. I wish, however, to emphasize the principle that he established, as suggested by Kondoléon, that in this operation is produced

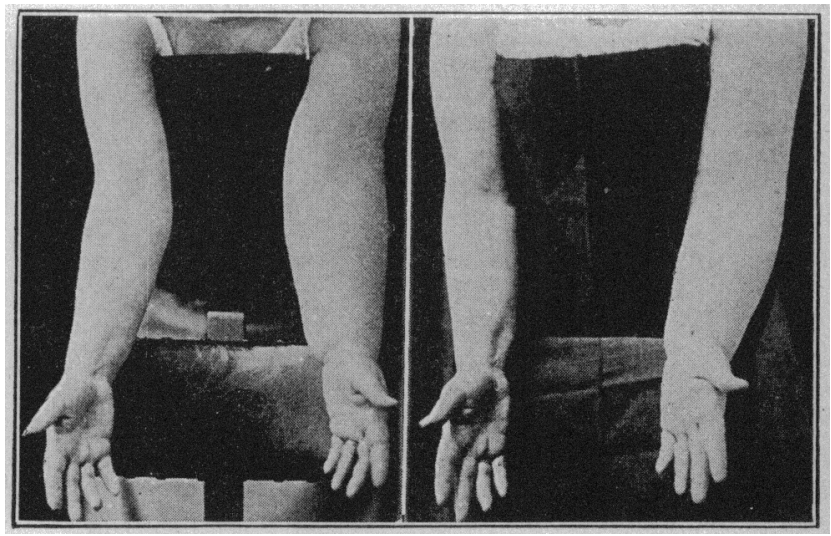

Fig. 13 (Case 3.)-Arm before operation and two and one-half months after operation.

an anastomosis or communication between the superficial and deep lymphatics by removing the barrier between them. This principle is a practical one, for in the cases in which it has been done, the result has worked out either for great improvement or almost perfect recovery. My patient was a colored man who had been living in Florida recently. The history extended over seven years, with recurring attacks 
of local inflammation resembling erysipelas. This again goes to show that in most of these cases there is an infection by the streptococcus of one type or another and during the period of the disease are exhibited, from time to time, recurring phases of this infection more or less acute. But very few observers have been able to prove the existence of the streptococcus in the tissues removed. My case was a typical Barbados leg and affected the limb only, from the knee down. There was a peculiar mass very horny, almost calcareous above the great toe. The bleeding at operation is usually quite free, and has to be controlled by hot packing and some ligatures. This case finally resulted in my having to operate on the foot in the same way three months afterward, and now the man's leg is practically well and he can perform his duties as a cook in a lumber camp.

Dr. H. B. Gessner, New Orleans: Dr. Sistrunk is to be congratulated on his excellent results and on his development of the technic. In regard to the etiology, there is no question about the importance of infection in producing these cases. As to the Filaria sanguinis-hominis, it must be extremely rare in this country. There is a tradition in New Orleans of a case in the Charity Hospital many years ago in which somebody found the Filaria sanguinishominis; the story is told how the investigator used to get up at midnight to take the blood and find the filariae dancing around. I have never known a case produced by filariae.

In addition to the one referred to by Dr. Sistrunk, I have had two other cases. In one of my cases the leg alone was involved, in another the forearm, in another the leg and thigh throughout their entire extent. In each of these cases there was a history of fascial and subcutaneous infection, not of an erysipelatous character. But I have seen a case in a middle aged womar in whom quite a considerable elephantiasis was traced to repeated attacks of erysipelas. The case in the forearm began in a finger infection. All of my patients were much improved, but none were cured entirely.

Dr. Matas has had half a dozen cases. In one the return to normal was almost complete.

Just a last word about the technic. We have not modified the technic, but our custom is to make a long incision on each side of the limb, through which the deep fascia is taken out quite extensively. I should estimate that in a leg we would probably take out half of the circumference of the deep fascia.

Dr. H. R. DECkER, Pittsburgh: Is an effort made to spare the internal saphenous vein by a median incision?

Dr. Walter E. Sistrunk, Rochester, Minn.: In answer to the question regarding the saphenous vein, we sacrifice that in removing the aponeurosis covering the muscles. It is along the line of incision and is deliberately cut with no bad results.

Cause of Leukemia.-The Nederlandsch Tijdschrift summarizes an article by Wiczkowski in the Przeglad Lekarski relating that he succeeded in inducing a disease in a hen, resembling in some respects human leukemia, by intravenous injection of pleural effusion from a young man who had developed acute leukemia after a trauma. The leukocytes numbered 590,000 and there was pleurisy on one side. In the hen the hemoglobin dropped from 55 to 9 per cent. and the bone marrow showed infiltrates, etc. The clinical picture differed completely from that with so-called fowl leukemia.

\section{TREATMENT OF VERNAL CONJUNC- TIVITIS WITH RADIUM \\ TECHNIC}

WILLIAM ALLEN PUSEY, M.D.

CHICAGO

In the course of the last fifteen years, I have treated with roentgen rays or radium several cases of vernal conjunctivitis. The results with either agent seem to be the same, and the application of the radium to the inner surface of the eyelids is so much less difficult than that of roentgen rays that in the last few years I have used only radium. I have had a great many requests for the technic of using radium in these cases. For that reason, I believe it may be interesting to describe the technic that I have found successful in my cases.

The lid to be treated is everted and held in the everted position by clamping lightly with lid forceps, such as are illustrated herewith. The blade next to the eye is of solid heavy metal, so that it prevents the eye itself being reached by an appreciable amount of rays. The outer blade consists of a rim with a large opening which leaves exposed the area of conjunctiva for the application of the radium. I have used in these cases a flat radium applicator containing in varnish $5 \mathrm{mg}$. of radium element. This applicator is of sufficient strength to produce a bright erythema on normal skin by an application of ten minutes through thin rubber cloth.

In order to avoid discomfort, I do not make any pressure in applying the radium to the lid, but pass it back and forth over the lid just short of the point of contact with the surface. I have estimated that in an application applied to the whole papebral conjunctiva with the applicator moving about, each part of the surface of the conjunctiva gets an exposure of onethird the total application; that is, with an application of thirty minutes, the applicator being moved back and forth, each part of the lid gets an exposure of ten minutes. I have preferred to make the application in broken doses. I make an application of five minutes' duration over the whole lid for six successive days, so that in the course of a week the conjunctiva gets thirty minutes of a moving exposure, each part of the lid thus getting ten minutes. This exposure with my applicator has not proved sufficient to give any evidence of roentgen-ray reaction. After such treatment, the patient is usually allowed an interval of several months, depending on the condition of the conjunctivitis. Usually the first series of treatments is followed by distinct improvement. In one successful case, I gave four series of such exposures in the course of a year without at any time producing an apparent radium reaction in the case, but obtaining a completely successful symptomatic result. 